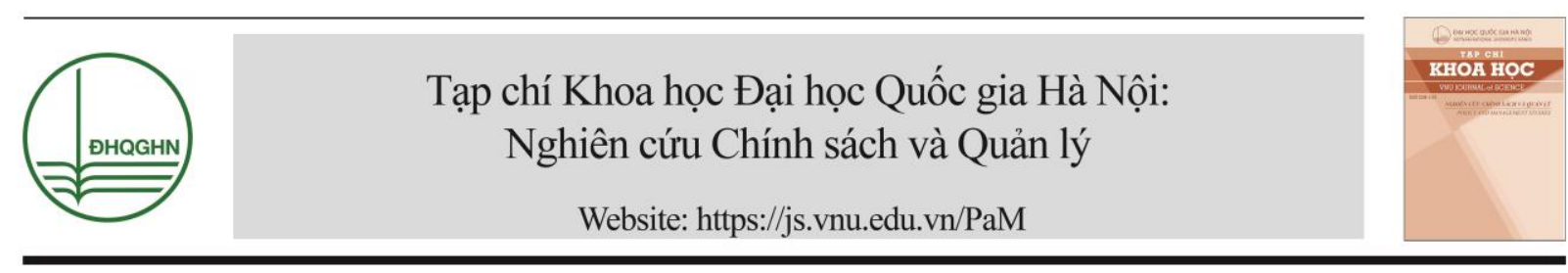

\title{
Đổi mới mô hình tăng trưởng kinh tế ở Việt Nam
}

\author{
Vũ Thị Thu Hương* \\ Khoa Triết học, Học viện Báo chí và Tuyên truyền, 36 Xuân Thủy, Hà Nội, Việt Nam \\ Nhận ngày 16 tháng 8 năm 2017 \\ Chỉnh sửa ngày 20 tháng 9 năm 2017; Chấp nhận đăng ngày 10 tháng 10 năm 2017
}

\begin{abstract}
Tóm tắt: Chủ trương đổi mới toàn diện kinh tế và chủ trương đổi mới mô hình tăng trưởng, tái cơ cấu nền kinh tế của Đảng Cộng sản Việt Nam được đề ra trong hai giai đoạn lịch sử khác nhau. Chủ trương đổi mới được đề ta từ Đại hội VI (1986), xác định trọng tâm là đổi mới toàn diện nền kinh tế, chuyển nền kinh tế từ tự cung, tự cấp sang nền kinh tế thị trường định hướng xã hội chủ nghĩa có sự quản lý của Nhà nước. Tiếp nối tư duy đổi mới kinh tế của Đảng đề ra từ Đại hội VI, Đảng ta đề ra chủ trương đổi mới toàn diện kinh tế, đổi mới mô hình tăng trưởng, tái cơ cấu lại nền kinh tế được đề ra từ Đại hội XI (2011), được bổ sung phát triển trong Đại hội XII (2016).
\end{abstract}

Tù khóa: Đổi mới kinh tế, đổi mới mô hình tăng trưởng, tái cơ cấu nền kinh tế, Đảng Cộng sản Việt Nam.

\section{Mở đầu}

Đường lối đổi mới của Đảng được đề ra từ Đại hội VI đến nay đã hơn 30 năm và đạt được những thành tựu to lớn có ý nghĩa lịch sử. Tuy nhiên, trong những năm gần đây, nền kinh tế nước ta đã bộc lộ không ít yếu kém nội tại. Tăng trưởng GDP tuy vẫn ở mức tương đối cao nhưng đang có xu hướng chậm lại; chất lượng tăng trưởng, hiệu quả và năng lực cạnh tranh của nền kinh tế còn thấp. Thực trạng này, trước hết là do mô hình tăng trưởng đã không còn phù hợp, không còn khả năng duy trì tăng trưởng cao và bền vững; cơ cấu kinh tế chưa hợp lý, chưa phù hợp với điều kiện thực tiễn. Vì vậy,

\footnotetext{
*ĐT.: 84-979888519.

Email: huongvtt84@gmail.com

https://doi.org/10.25073/2588-1116/vnupam.4131
}

việc lựa chọn mô hình tăng trưởng sao cho vừa thúc đẩy nền kinh tế phát triển, tăng nhanh thu nhập, cải thiện đời sống dân cư mà không bị rơi vào bẫy thu nhập trung bình, vừa giải quyết được vấn đề xã hội và bảo vệ môi trường sinh thái là một trong những vấn đề cơ bản của chính sách kinhy tế nước ta hiện nay và trong tương lai.

\section{Quan điểm của Đảng về đổi mới mô hình tăng trưởng kinh tế}

Chủ trương đổi mới toàn diện nền kinh tế được Đảng đề ra từ Đại hội VI (1986). Trước đó, do chưa thừa nhận sản xuất hàng hóa và cơ chế thị trường, Đảng ta đã xem kế hoạch hóa là đặc trưng quan trọng nhất của kinh tế xã hội chủ nghĩa, phân bồ mọi nguồn lực theo kế 
hoạch là chủ yếu; phủ nhận thị trường hoặc chỉ coi nó là một công cụ thứ yếu bổ sung cho kế hoạch. Không thừa nhận trên thực tế sự tồn tại của nền kinh tế nhiều thành phần trong thời kỳ quá độ, lấy kinh tế quốc doanh và kinh tế tập thể là hai khu vực kinh tế chủ yếu, muốn nhanh chóng xóa bỏ sở hữu tư nhân và kinh tế cá thể; xây dựng hệ thống kinh tế khép kín. Kết quả là nền kinh tế rơi vào tình trạng trì trệ, khủng hoảng, mất cân đối nghiêm trọng: Cơ sở vật chất kỹ thuật yếu kém, thiếu đồng bộ, lạc hậu, cũ nát, lao động thủ công là chủ yếu, phân công lao động kém phát triển, sản phẩm làm ra không đáp ứng được yêu cầu tiêu dùng, làm không đủ ăn phải dựa vào nguồn viện trợ từ bên ngoài. Phân phối lưu thông rối ren, thị trường tài chính, tiền tệ không ổn định, hoạt động thương mại bị ngăn cấm, đời sống nhân dân gặp nhiều khó khăn, thiếu thốn, tình hình chính trị xã hội tiềm ẩn nhiều nguy cơ bất ổn.

Từ thực tiễn đó của nền kinh tế, Đại hội VI của Đảng đã thẳng thắn chỉ ra những hạn chế trong nhận thức về tư duy kinh tế, những khiếm khuyết của mô hình kinh tế xã hội chủ nghĩa tập trung - quan liêu - bao cấp, những sai lầm hạn chế trong quản lý, điều hành nền kinh tế. Đổi mới cơ chế quản lý kinh tế trở thành nhu cầu cấp thiết và hết sức cấp bách lúc bấy giờ để đưa đất nước thoát khỏi khủng hoảng kinh tế - xã hội, Đảng đã đưa ra chủ trương mang tính bước ngoặt trong quản lý nền kinh tế. Đó là quyết định đổi mới toàn diện nền kinh tế, chuyển nền kinh tế từ tự cung, tự cấp sang nền kinh tế thị trường định hướng xã hội chủ nghĩa có sự quản lý của Nhà nước. Bước đột phá trong chủ trương này là thay đổi cơ chế quản lý kinh tế từ khâu sản xuất đến khâu lưu thông. Đại hội VI khẳng định: "Việc bố trí lại cơ cấu kinh tế phải đi đôi với đổi mới cơ chế quản lý kinh tế. Cơ chế quản lý tập trung quan liêu, bao cấp từ nhiều năm nay không tạo được động lực phát triển, làm suy yếu kinh tế xã hội chủ nghĩa, hạn chế việc sử dụng và cải tạo các thành phần kinh tế khác, kìm hãm sản xuất, làm giảm năng suất, chất lượng, hiệu quả, gây rối loạn trong phân phối, lưu thông và làm nảy sinh nhiều hiện tượng tiêu cực trong xã hội” [1, tr.62].
Để thực hiện chủ trương đổi mới chiến lược nền kinh tế, Đảng ta đề ra ba chương trình kinh tế lớn: lương thực - thực phẩm, hàng tiêu dùng, hàng xuất khẩu, và Đảng ta khẳng định "Ba chương trình này liên quan chặt chẽ với nhau, là cơ sở và tiền đề cho nhau... Ba chương trình lớn là cốt lõi của nhiệm vụ kinh tế - xã hội trong năm 1986 - 1990, không những có ý nghĩa sống còn trong tình hình trước mắt, mà còn là những điều kiện ban đầu không thể thiếu để triển khai công nghiệp hóa xã hội chủ nghĩa trong chặng đường tiếp theo" $[1$, tr.47]. Đây là quyết sách khởi nguồn cho những thành tựu kinh tế của Việt Nam hơn 30 năm đổi mới.

Quan điểm của Đảng về đổi $\mathrm{m}$ ới mô hình tăng trưởng kinh tể tại Đại hội VI tiếp tục được cụ thể hóa tại các đại hội sau đó. Tại Đại VII, Đảng chủ trương tiếp tục đổi mới toàn diện và đồng bộ, đưa công cuộc đổi mới đi vào chiều sâu với bước đi vững chắc; chủ trương tiếp tục xây dựng nền kinh tế hàng hóa nhiều thành phần, đồi mới quản lý kinh tế; phát huy thế mạnh của các thành phần kinh tế, vừa cạnh tranh, vừa hợp tác, bổ sung cho nhau trong nền kinh tế quốc dân. Sau 10 năm đổi mới nền kinh tế - xã hội không ngừng ổn định và phát triển, tại Đại hội VIII năm 1996, Đảng ta xác định mục tiêu trọng tâm trong phát triển kinh tế là đẩy mạnh thực hiện công nghiệp hóa, hiện đại hóa; tiếp tục khẳng định và nhấn mạnh chủ trương xây dựng nền kinh tế thị trường phát triển theo định hướng xã hội chủ nghĩa. Tại Đại hội IX sau khi đánh giá những thành tựu đạt được và những hạn chế, đặc biệt là trình độ phát triển còn thua kém, nguy cơ tụt hậu về kinh tế càng xa hơn; do đó, Đại hội khẳng định thực hiện nhất quán và lâu dài chính sách phát triển kinh tế hàng hóa nhiều thành phần vận động theo cơ chế thị trường có sự quản lý của Nhà nước theo định hướng xã hội chủ nghĩa. Đại hội IX, Đảng đồng thời khẳng định cần xây dựng quan hệ sản xuất phù hợp với trình độ phát triển của lực lượng sản xuất, theo hướng: cùng với sự phát triển của lực lượng sản xuất hiện đại, trong mỗi vùng, mỗi ngành vẫn còn phải chuyê̂n biến sản xuất từ thấp đến cao, từ kinh tế tự cung, tự cấp lên sản xuât hàng hóa nhỏ, từ sản xuất hàng 
hóa nhỏ lên sản xuất hàng hóa tư nhân, tư bản nhà nước, kinh tế cá thể tiến lên kinh tế tập thể... Tại Đại hội X, Đảng nhấn mạnh đến việc hoàn thiện thể chế kinh tế thị trường định hướng xã hội chủ nghĩa; đẩy mạnh công nghiệp hóa, hiện đại hóa gắn với kinh tế tri thức; trong đó, phải coi kinh tế tri thức là yếu tố quan trọng thâm nhập vào từng lĩnh vực của nền kinh tế, phát triển các ngành kinh tế và các sản phẩm kinh tế phải có giá trị gia tăng cao dựa nhiều vào tri thức.

Đến Đại hội XI (2011), Đảng đã đề ra một chủ trương mới, chủ trương chuyển đổi mô hình tăng trưởng, tái cơ cấu nền kinh tế gắn với thực hiện 3 bước đột phá chiến lược được Đảng xác định đã trở thành chủ trương lớn, thu hút toàn bộ hệ thống chính trị cùng vào cuộc. Mục tiêu của việc tái cơ cấu kinh tế là thay đổi thể chế, cơ chế, công cụ phân bổ, quản lý và sử dụng nguồn lực quốc gia theo mô hình tăng trưởng mới với cơ cấu kinh tế hợp lý hơn, hiệu quả hơn, nâng cao khả năng cạnh tranh của nền kinh tế, bảo đảm phát triển bền vững và phù hợp với xu hướng toàn cầu hóa. Tái cơ cấu nền kinh tế và đổi mới mô hình tăng trưởng phải gắn kết hữu cơ với nhau, tác động lẫn nhau, trong đó mô hình tăng trưởng có vai trò dẫn dắt, chi phối quá trình tái cơ cấu nền kinh tế. Ngược lại, tái cơ cấu nền kinh tế là điều kiện tiên quyết để đổi mới mô hình tăng trưởng. Đảng cũng nhấn mạnh, việc tái cơ cấu nền kinh tế, đổi mới mô hình tăng trưởng phải gắn với thực hiện 3 khâu đột phá chiến lược, bao gồm: Hoàn thiện thể chế kinh tế thị trường định hướng xã hội chủ nghĩa; phát triển nguồn nhân lực; xây dựng hệ thống kết cấu hạ tầng. Từ chủ trương đó, hàng loạt chính sách mới được Đảng và Nhà nước ban hành như chính sách tập trung công nghiệp hóa, hiện đại hóa nông nghiệp, nông thôn; chính sách nhằm thay đỏi mô hình tăng trưởng gắn với 3 khâu đột phá chiến lược nhằm hoàn thiện mô hình nền kinh tế thị trường định hướng xã hội chủ nghĩa.

Tiếp nối chủ trương, đường lối của Đại hội XI của Đảng về đổi mới mô hình tăng trưởng, tái cấu trúc lại nền kinh tế mạnh mẽ hơn nữa, Đại hội XII của Đảng xác định định hướng đổi mới mô hình tăng trưởng trong thời gian tới: “... kết hợp có hiệu quả phát triển chiều rộng với chiều sâu, chú trọng phát triển chiều sâu, nâng cao chất lượng tăng trưởng và sức cạnh tranh..." [2, tr.87]. Trong đó, Đảng nhấn mạnh chuyển đổi mô hình tăng trưởng từ chủ yếu dựa vào xuất khẩu và vốn sang đầu tư và phát triển đồng thời dựa cả vào vốn đầu tư, xuất khẩu và thị trường trong nước. Phát huy vai trò quyết định của nội lực, đồng thời thu hút, sử dụng có hiệu quả các nguồn lực bên ngoài; phát huy đầy đủ đúng đắn vai trò của doanh nghiệp nhà nước, doanh nghiệp tư nhân, doanh nghiệp FDI và sản xuất nông nghiệp. Đẩy nhanh nghiên cứu, ứng dụng khoa học tiến bộ khoa học - công nghệ và đổi mới sáng tạo để nâng cao năng suất lao động, thúc đẩy nghiên cứu và triển khai (R\&D), nhập khẩu công nghệ mới; thực hiện phương thức quản lý, quản trị hiện đại; phát huy tiềm năng con người và khuyến kích tinh thần sản xuất kinh doanh từ mọi người để chủ động khai thác lợi thế cạnh tranh, nâng cao giá trị gia tăng, tăng nhanh giá trị quốc gia và tham gia có hiệu quả vào chuỗi giá trị toàn cầu.

Về việc cơ cấu lại đồng bộ, tổng thể nền kinh tế, Văn kiện Đại hội XII của Đảng nhấn mạnh đến việc tiếp tục đẩy mạnh thực hiện cơ cấu lại đồng bộ, tổng thể nền kinh tế và các ngành, các lĩnh vực gắn với đổi mới mô hình tăng trưởng, tập trung vào các lĩnh vực quan trọng: cơ cấu lại đầu tư với trọng tâm là đầu tư cồng, cơ cấu lại thị trường tài chính với trọng tâm là hệ thống ngân hàng thương mại và các tổ chức tài chính, từng bước cơ cấu lại ngân sách nhà nước; cơ cấu lại và giải quyết có hiệu quả vấn đề nợ xấu, bảo đảm an toàn nợ công; cơ cấu lại doanh nghiệp nhà nước với trọng tâm là các tập đoàn, tổng công ty nhà nước; cơ cấu lại nông nghiệp theo hướng nâng cao giá trị gia tăng, gắn phát triển kinh tế nông thôn với xây dựng nông thôn mới.

Đại hội XII của Đảng cũng nhấn mạnh việc tiếp tục đẩy mạnh thực hiện ba đột phá chiến lược do Đại hội XI của Đảng đề ra, trong đó, tập trung nhất là "đột phá về thể chế kinh tế thị trường định hướng xã hội chủ nghĩa, nhằm giải phóng mạnh mẽ sức sản xuất, huy động, 
phân bổ, sử dụng có hiệu quả các nguồn lực" [2, tr.89].

Đại hội XII của Đảng trên cơ sở đánh giá những thành tựu và hạn chế sau 5 năm thực hiện chủ trưởng của Đại hội XI về tái cơ cấu nền kinh tế, đã đề ra những chủ trương lớn về tiếp tục đổi mới mô hình tăng trưởng và tái cấu trúc lại nền kinh tế mạnh mẽ hơn. Những chủ trương lớn về đổi mới mô hình tăng trưởng và tái cơ cấu nền kinh tế của Đảng là định hướng trong xây dựng kinh tế cho 5 năm tiếp theo (2016 - 2020) và các giai đoạn sau.

\section{Thành tựu và hạn chế trong đổi mới mô hình tăng trương kinh tế}

Sự nghiệp đổi mới đất nước được xem là một giai đoạn quan trọng trong sự nghiệp phát triển của nước ta. Sau hơn 30 năm thực hiện sự nghiệp đổi mới, đất nước ta đã đạt được những thành tựu to lớn. Trong Văn kiện Đại hội XII của Đảng, phần "Nhìn lại 30 năm đồi mới (1986 - 2016)", khi đánh giá thành tựu, Đảng ta khẳng định: "Đất nước ra khỏi khủng hoảng kinh tế - xã hội và tình trạng kém phát triển, trở thành nước đang phát triển có thu nhập trung bình, đang đẩy mạnh công nghiệp hóa, hiện đại hóa, hội nhập quốc tế. Kinh tế tăng trưởng khá, nền kinh tế thị trường định hướng xã hội chủ nghĩa từng bước hình thành, phát triển..." $[2$, tr.65-66]. Đánh giá 30 năm đổi mới, Đảng đã khẳng định nhờ có sự nghiệp đổi mới kinh tế, nước ta từng bước thoát khỏi khủng hoảng kinh tế - xã hội, kinh tế tăng trưởng nhanh, hệ thống cơ sở vật chất được tăng cường. Tốc độ tăng trưởng được duy trì và ổn định qua nhiều năm, trung bình khoảng $6 \%$ đến $7 \% /$ năm. Ví dụ như năm 2012, mặc dù kinh tế thế giới có nhiều khó khăn, nhiều nước mức tăng trưởng âm, nhưng Việt Nam vẫn đạt mức tăng trưởng 5,03\%. Năm 2016, tốc độ tăng trưởng $6,21 \%$ và năm 2017 tăng trưởng kinh tế đã đạt là $6,81 \%$, hơn mọi dự báo lạc quan nhất trước đó. Từ những năm 2010, Việt Nam đã thoát khỏi nhóm nước chậm phát triển và bước vào nhóm nước có thu nhập trung bình thấp. Nhờ tăng trưởng kinh tế trong nhiều năm, Việt Nam có điều kiện cải thiện mức sống của nhân dân, hệ thống an sinh xã hội và phúc lợi xã hội được hoàn thiện và nâng cao. Hệ thống kết cấu hạ tầng được đầu tư và không ngừng được mở rộng và nâng cao chất lượng... Thành tựu đạt được đã chứng minh cho sự đúng đắn, sáng tạo trong đường lối lãnh đạo của Đảng.

Bên cạnh thành tựu đạt được, những năm gần đây, nền kinh tế Việt Nam bắt đầu bộc lộ ngày càng rõ những khiếm khuyết trong mô hình tăng trưởng và phát triển kinh tế - xã hội. Kinh tế phát triển thiếu bền vững. Chất lượng tăng trưởng giảm, năng suất, hiệu quả và sức cạnh tranh của nền kinh tế thấp, các cân đối kinh tế vĩ mô chưa vững chắc. Trong giai đoạn đổi mới vừa qua, tăng trưởng của kinh tế Việt Nam chủ yếu dựa vào các yếu tố phát triển theo chiều rộng, chậm chuyển sang tăng trưởng theo chiều sâu. Từ cuối năm 2007, những tác động tiêu cực của khủng hoảng tài chính toàn cầu và suy thoái kinh tế trên thế giới tác động mạnh vào nền kinh tế nước ta đã làm bộc lộ nhiều hạn chế trong mô hình phát triển kinh tế này. Mặc dù Đảng và Nhà nước đã có chủ trương và nhiều giải pháp, nhiều chỉnh sách cấp bách ngăn chặn đà suy giảm, duy trì tăng trưởng kinh tế hợp lý, đảm bảo an sinh xã hội, song vẫn chưa giải quyết được các vấn đề hạn chế, yếu kém của nền kinh tế. Kinh tế Việt Nam tiếp tục gặp những khó khăn. Nguy cơ lạm phát và những bất ổn kinh tế vĩ mô toàn cầu tác động tiêu cực đến nền kinh tế Việt Nam. Những khiếm khuyết của mô hình kinh tế bắt đầu gây ra những hậu quả nghiêm trọng, ảnh hưởng tới mọi mặt của đời sống xã hội. Mức tăng trưởng của nền kinh tế bắt đầu chậm dần, chất lượng và sức cạnh tranh tiếp tục suy giảm, tỷ giá thiếu ổn định, lạm phát có nguy cơ tăng cao trở lại. Nhìn chung nền kinh tế phát triển không bền vững, thị trường rối loạn, đặc biệt là các thị trường trọng điểm, như thị trường vốn, thị trường tài chính, thị trường vàng, thị trường bất động sản... Một số thị trường quan trọng khác chưa hình thành được như thị trường lao động, thị trường công nghệ. Chính sách điều hành kinh tế 
vĩ mô chưa hợp lý cũng tạo ra nhiều bất ổn, nhu tồn kho hàng hóa, đầu tư công dàn trải, thất thoát, kém hiệu quả, doanh nghiệp Nhà nước hoạt động thua lô̂, nợ xấu khó xử lý, hệ thống tài chính, ngân hàng bấp bênh, không an toàn, sản xuất kinh doanh gặp nhiều khó khăn. Nguy cơ mất ổn định kinh tế vĩ mô tăng cao gây tâm lý lo lắng trong đại bộ phận nhân dân.

Nguyên nhân dẫn đến nguy cơ mất ổn định của nền kinh tế được Đảng xác định là do hạn chế của cơ cấu nền kinh tế và mô hình tăng trưởng. Nhiều năm qua, cơ cấu nền kinh tế được thiết kế và vận hành nhằm phục vụ mục tiêu tăng trưởng nóng. Mặc dù các nền tảng căn bản của một nền kinh tế thị trường trong điều kiện hội nhập còn thiếu và yếu song vẫn được chấp nhận và vận hành nền kinh tế theo mô hình tăng trường về bề rộng. Mô hình tăng trưởng kinh tế này có phát huy tác dụng tích cực và hiệu quả trong giai đoạn đầu của thời kỳ đổi mới, giải phóng được các nguồn lực sản xuất, cải thiện đáng kể chất lượng đời sống của nhân dân. Nhưng tăng trưởng theo mô hình này có được chủ yếu là nhờ tăng đầu tư. Đa số các ngành sản xuất hoạt động gia công phục vụ xuất khẩu. Sản phẩm của nền kinh tế là những sản phẩm thô, giá trị gia tăng thấp. Việc duy trì quá lâu mô hình tăng trưởng này khiến cho những yếu kém nội tại của nền kinh tế với cơ cấu không hợp lý, hiệu quả thấp càng tích tụ, bị dồn nén. Khi Việt Nam hội nhập ngày càng sâu rộng, chịu sự tác động trực tiếp của nền kinh tế khu vực và trên thế giới, thì những yếu kém nội tại đó bắt đầu bộc phát và gây ra những hệ lụy nguy hại, khó lường. Lại một lần nữa, nền kinh tế Việt Nam rơi vào khủng hoảng nếu không có những quyết sách lớn tầm vĩ mô.

Bối cảnh nền kinh tế, chính trị - xã hội nêu trên đòi hỏi Đảng phải có những hành động quyết liệt và thiết thực, đổi mới tư duy về cơ cấu kinh tế. Yêu cầu, nhiệm vụ cấp thiết lúc này cũng giống như yêu cầu và nhiệm vụ những năm bắt đầu đổi mới nhưng ở những khía cạnh, những giá trị lợi ích cao hơn, phức tạp hơn. Nhiệm vụ trọng tâm, cấp bách hàng đầu trong giai đoạn hiện nay là ổn định kinh tế vĩ mô, đảm bảo cho nền kinh tế phát triển bền vững, tiếp tục cải thiện, nâng cao đời sống vật chất, tinh thần cho nhân dân, ổn định trật tự xã hội. Nhận thức được thực trạng đó, Đại hội XI (2011) của Đảng đã đề ra nhiệm vụ đồi mới mô hình tăng trưởng, cơ cấu lại nền kinh tế theo hướng: "Chuyển đổi mô hình tăng trưởng từ chủ yếu phát triển theo chiều rộng sang phát triển hợp lý giữa chiều rộng và chiều sâu, vừa mở rộng quy mô, vừa chú trọng nâng cao chất lượng, hiệu quả, tính bền vững. Thực hiện cơ cấu lại nền kinh tế, trọng tâm là cơ cấu lại các ngành sản xuất, dịch vụ phù hợp với các vùng; thúc đẩy cơ cấu lại doanh nghiệp và điều chỉnh chiến lược thị trường; tăng nhanh giá trị nội địa, giá trị gia tăng và sức cạnh tranh của sản phẩm, doanh nghiệp và của cả nền kinh tế; phát triển kinh tế tri thức" [3, tr.107].

Sau 5 năm thực hiện chủ trương của Đảng về tái cơ cấu nền kinh tế, trong Đại hội XII của Đảng đã đánh giá khái quát kết quả đạt được: "Mô hình tăng trưởng từ chủ yếu theo chiều rộng đã từng bước chuyển dần sang kết hợp giữa chiều rộng và chiều sâu; đã hình thành những mô hình mới và cách làm mới, sáng tạo. Với việc cơ cấu lại nền kinh tế và thực hiện 3 đột phá chiến lược, nhất là trên một số lĩnh vực trọng tâm, năng suất, hiệu quả và sức cạnh tranh của nền kinh tế có bước cải thiện; bảo đảm hài hòa hơn giữa tăng trưởng kinh tế với thực hiện tiến bộ và công bằng xã hội, bảo vệ tài nguyên môi trường" [2, tr.82]. Tuy nhiên, bên cạnh những kết quả đạt được, quá trình thực hiện cơ cấu lại nền kinh tế còn tồn tại nhiều hạn chế, Đại hội đã chỉ rõ: "Nền kinh tế vẫn chủ yếu phát triển theo chiều rộng, tăng trưởng còn dựa nhiều vào các yếu tố về vốn, tài nguyên, lao động trình độ thấp, chưa dựa vào tri thức, khoa học và công nghệ, lao động có kỹ năng. Năng suất lao động chậm được cải thiện, thấp hơn nhiều một số nước trong khu vực. Đóng góp của năng suất các nhân tố tổng hợp (TFP) vào tăng trưởng còn thấp. Chưa phát huy được lợi thế so sánh và tận dụng cam kết hội nhập quốc tế để nâng cao chất lượng tăng trưởng, phát triển bền vững" [2, tr.84-85]. 


\section{Kết luận}

Chủ trương đổi mới mô hình tăng trưởng kinh tế được đặt ra tại Đại hội VI và được cụ thể hóa tại các đại hội tiếp theo phù hợp với điều kiện thực tiễn đất nước và xu thế quốc tế hiện nay. Việc thực hiện chủ trương đó đã làm cho nền kinh tế nước ta ngày càng phát triển và hội nhập với nền kinh tế thế giới. Tuy nhiên, mô hình tăng trưởng kinh tế vẫn cần tiếp tục được đổi mới hơn nữa để đạt được mục tiêu phát triển nhanh và bền vững.

\section{Tài liệu trích dẫn}

[1] Đảng Cộng sản Việt Nam, Văn kiện Đại hội đại biểu toàn quốc lần thứ VI, Nxb Sự thật, Hà Nội, 1987.

[2] Đảng Cộng sản Việt Nam, Văn kiện Đại hội đại biểu toàn quốc lần thứ XII, Nxb Chính trị quốc gia, Hà Nội, 2016.

[3] Đảng Cộng Sản Việt Nam, Văn kiện Đại hội đại biểu toàn quốc lần thứ XI, Nxb Chính trị quốc gia, Hà Nội, 2011.

\title{
Reforming Economic Growth Model in Vietnam
}

\author{
Vu Thi Thu Huong \\ Faculty of Philosophy, Academy of Journalism and Communication, 36 Xuan Thuy, Hanoi, Vietnam
}

\begin{abstract}
The Communist Party of Vietnam's (CPV) policy of comprehensive economic renovation and reform of the economic growth model were proposed in two different historical periods. The economic renovation policy was proposed by the $6^{\text {th }}$ National Congress of the CPV (1986), which defined the focus of a comprehensive reform of the economy for transforming the economy from a self-sufficient economy to a socialist-oriented market one with the State management. Following the economic renovation, the $11^{\text {th }}$ National Congress of the CPV (2011) proposed the policy of renovation of the growth model and reconstruction of the economy, which was amended by the $12^{\text {th }}$ National Congress of the CPV (2016).

Keywords: Economic reform, development model reform, economy reconstruction, Communist Party of Vietnam
\end{abstract}

